\title{
DEVELOPMENT OF AN EXPERIMENTAL MODEL OF A FLOW METER-BATCHER OF VARIOUS INTENSITIES
}

\author{
Denis Shilin, Dmitry Shestov, Pavel Ganin, Nikolay Grebenshchikov, \\ Andrey Novikov \& Valery Moskvin
}
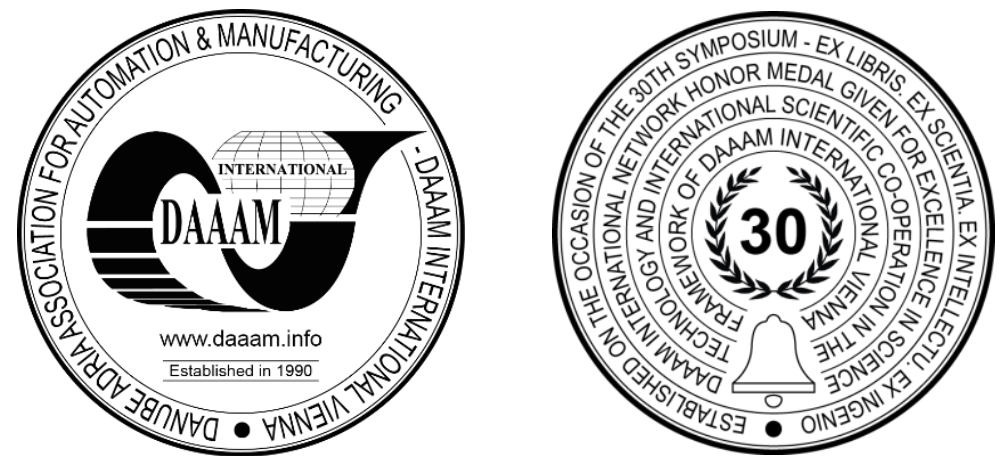

This Publication has to be referred as: Shilin, D[enis]; Shestov, D[mitry]; Ganin, P[avel]; Grebenshchikov, N[ikolay]; Novikov, A[ndrey] \& Moskvin, V[alery] (2020). Development of an Experimental Model of a Flow Meter-Batcher of Various Intensities, Proceedings of the 31st DAAAM International Symposium, pp.0098-0103, B. Katalinic (Ed.), Published by DAAAM International, ISBN 978-3-902734-29-7, ISSN 1726-9679, Vienna, Austria

DOI: $10.2507 / 31$ st.daaam.proceedings.013

\begin{abstract}
This work is devoted to the development of a prototype of a flow meter-batcher of various intensities, the design of which is intended for the subsequent study of the static error in determining the mass of the weighed bulk material passing through the installation in the entire range. permissible capacity of the batcher (from 5 tons / hour to 50 tons / hour). The article also discusses the architecture of an automatic control and management system developed for a laboratory facility, with the help of which the experiment will be remotely controlled. The authors of the work declare that the proposed kinematic model of the prototype will reduce not only the static error in weighing bulk material, but also reduce energy performance by developing a unique algorithm for controlling the conveyor belt electric motor.
\end{abstract}

Keywords: dispenser; kinematic diagram; strain gauge; productivity.

\section{Introduction}

The Russian Federation is a large center of the chemical and light industry developing in such areas as the production of polymers, household chemicals, pharmaceuticals and medical preparations, the production of rubbers, precious metals, chemical reagents, mechanical engineering and auto chemistry. [1]. Each production at one level or another implies continuous weighing of components for the manufacture or packaging of free-flowing mixtures. The weighing accuracy in these data directly affects the cost price and product quality. Dosing of components in a feed mill is an important technological stage. The dosage determines the volume of compound feed production, as well as the quality of the feed produced. Product development is currently carried out according to recipes used on a computer, since permanent recipes are practically not used [2], [3]. Permissible error depending on the component included in the feed mixture. So, with a fraction of $30 \%$ or more, the error is $<1.5 \%$, with $10 \ldots 30 \%<1.0 \%$, with a fraction less than $10 \%= \pm 0.5 \%$. When dosing mineral additives $= \pm 0.1 \%$, microelements $= \pm 0.01 \%$ [4]. The main problems of technological processes of modern lines and the methods of dosing feed components used in them differ from the used feed mixtures, as a rule, by an unjustifiably high level of energy consumption [5], [6], [7], [8]. The solution to this problem is possible by improving the kinematic scheme of the installation by placing two strain gauges along the edges from the side of loading bulk materials.

The aim of the work is to develop and manufacture a prototype of a flow meter-batcher based on an improved kinematic diagram of two strain gauges for studying the dispensing error in the entire range of permissible plant productivity (from 5 tons / hour to 50 tons / hour). To this end, this article also discusses the control system design for the proposed installation. 


\section{Description of the appearance of the flow meter-batcher}

As part of the work, design documentation was developed for a prototype of a flow meter-batcher (FMB) of various intensities, the appearance of which is shown in Figure 1. The presented installation simulates the operation of the FMB line, the adjustment of which is carried out by installing a unique flow section from the loading side. The main structural elements of an in-line flow meter-batcher of various intensities are: a metal frame - 1 and a design of a belt conveyor 16.

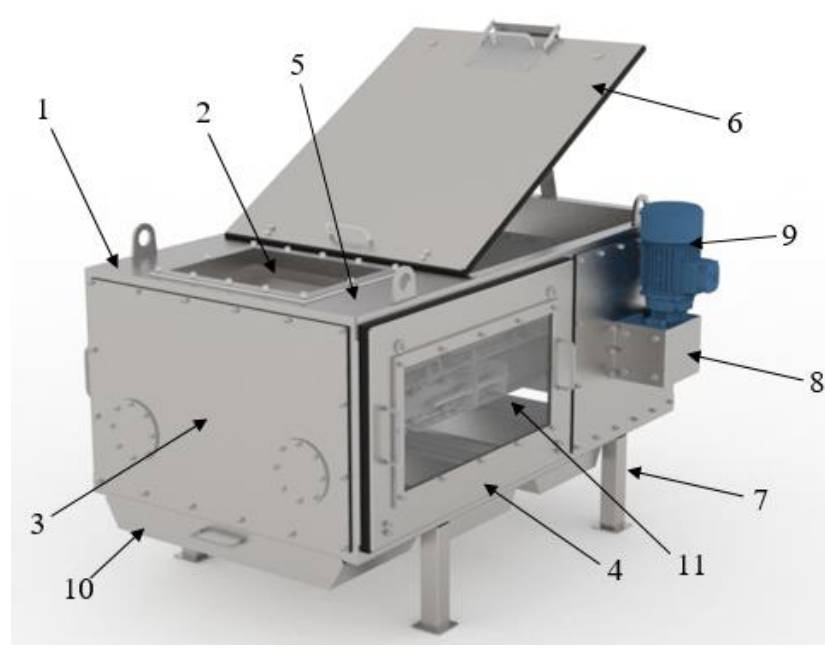

a)

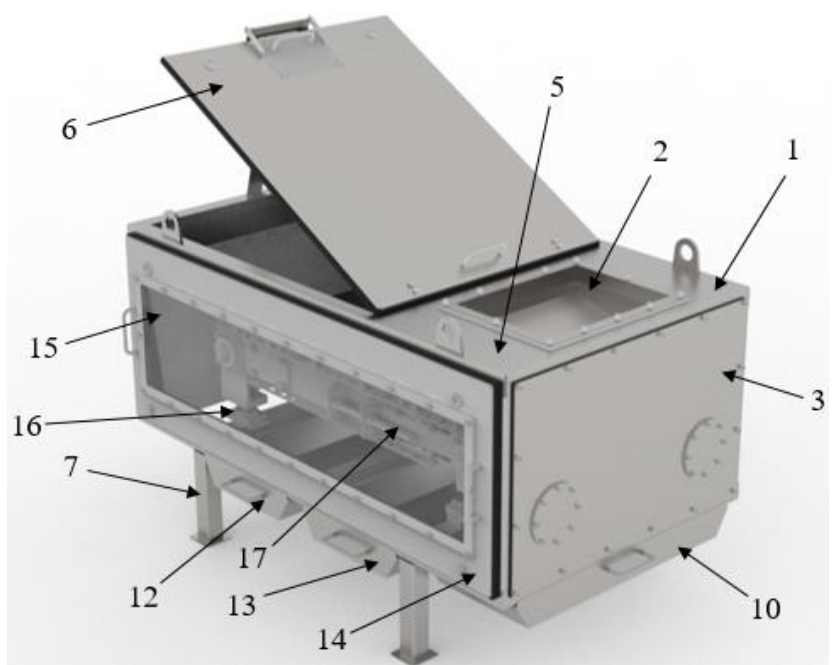

b)

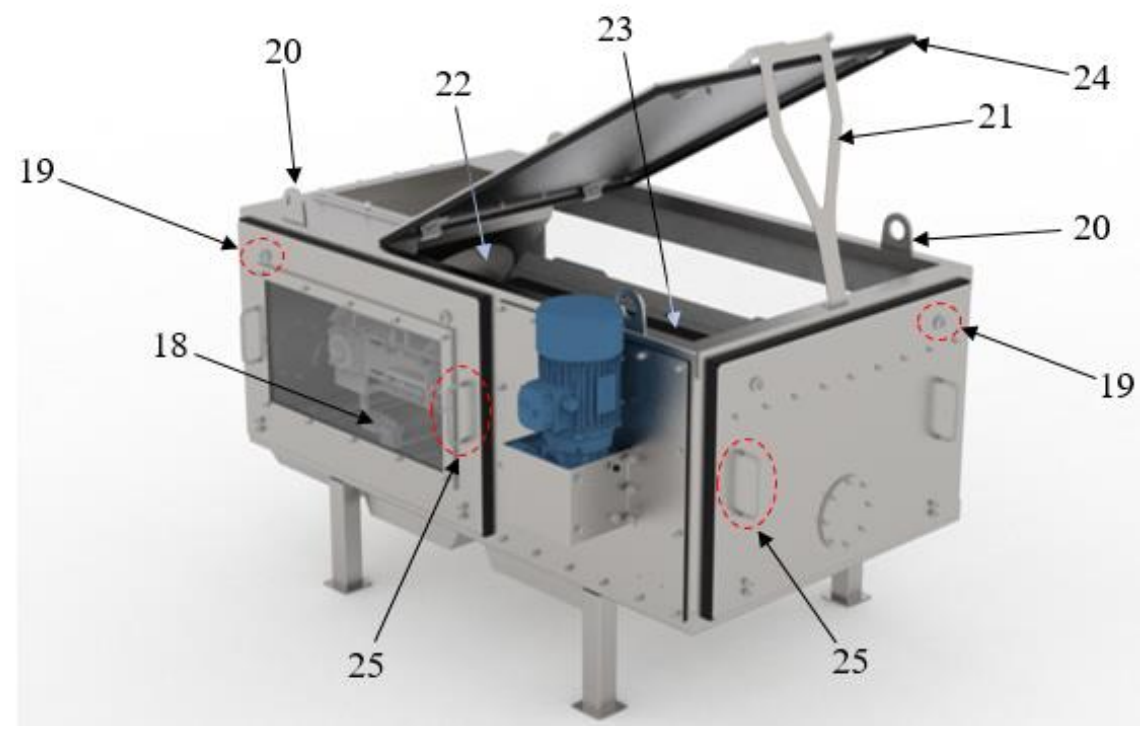

c)

Fig. 1. Appearance of the prototype flow meter-batcher of various intensities: a) front view 1, b) front view 2, c) rear view. 1 - metal frame, 2 - opening of the loading hopper, 3 - front wall, 4 - right wall, 5 - upper wall, 6 - upper cover, 7 leg (support), 8 - NMRV 050 gearbox, 9 - 5A80MA2 electric motor, 10 - tray 1, 11 - removable right cover, 12 - tray 2 , 13 - tray 3,14 - left wall, 15 - removable left cover, 16 - ball joint under the conveyor, 17 - belt conveyor structure, 18 force sensor, 19 - lock, 20 - anchor bolt, 21 - post, 22 - flow former, 23 - conveyor belt, 24 - rubber seal, 25 - handle

In turn, the FMB body consists of: the opening of the loading hopper 2; front wall 3; right wall 4; top wall 5; top cover 6; legs (supports) 7; trays 10, 12 and 13; 11 - removable right cover; left wall 14; left removable cover 15; spherical support of the conveyor 16; twist lock 19; anchor bolt 20; stands 21; flow former 22; rubber seal 24; handles 25.

The conveyor belt moves by means of an electric motor 9 through a gearbox 8 . The main structural elements of the belt conveyor are: conveyor belt 23, conveyor ball bearing 16; force sensor 18 . The design of the unit has removable walls for maintenance. Each wall is rubber-sealed around 24 to ensure a tight seal. To remove the wall, loosen the twist locks 19 and use the handles 25 . Anchor bolt 20 is designed to fasten the structure to the overhead crane for local movement and installation. The design of the conveyor in combination with force-measuring sensors 18 and ball bearings under the conveyor 16 is a kinematic diagram proposed by the authors, shown in Figure 2. 
The kinematic diagram of the flow-through flow meter-batcher consists of two strain gauges (D1, D2) installed along the edges from the loading side of bulk materials, a drive drum, on the shaft of which an asynchronous motor is fixed, a conveyor belt. (see figure 2).

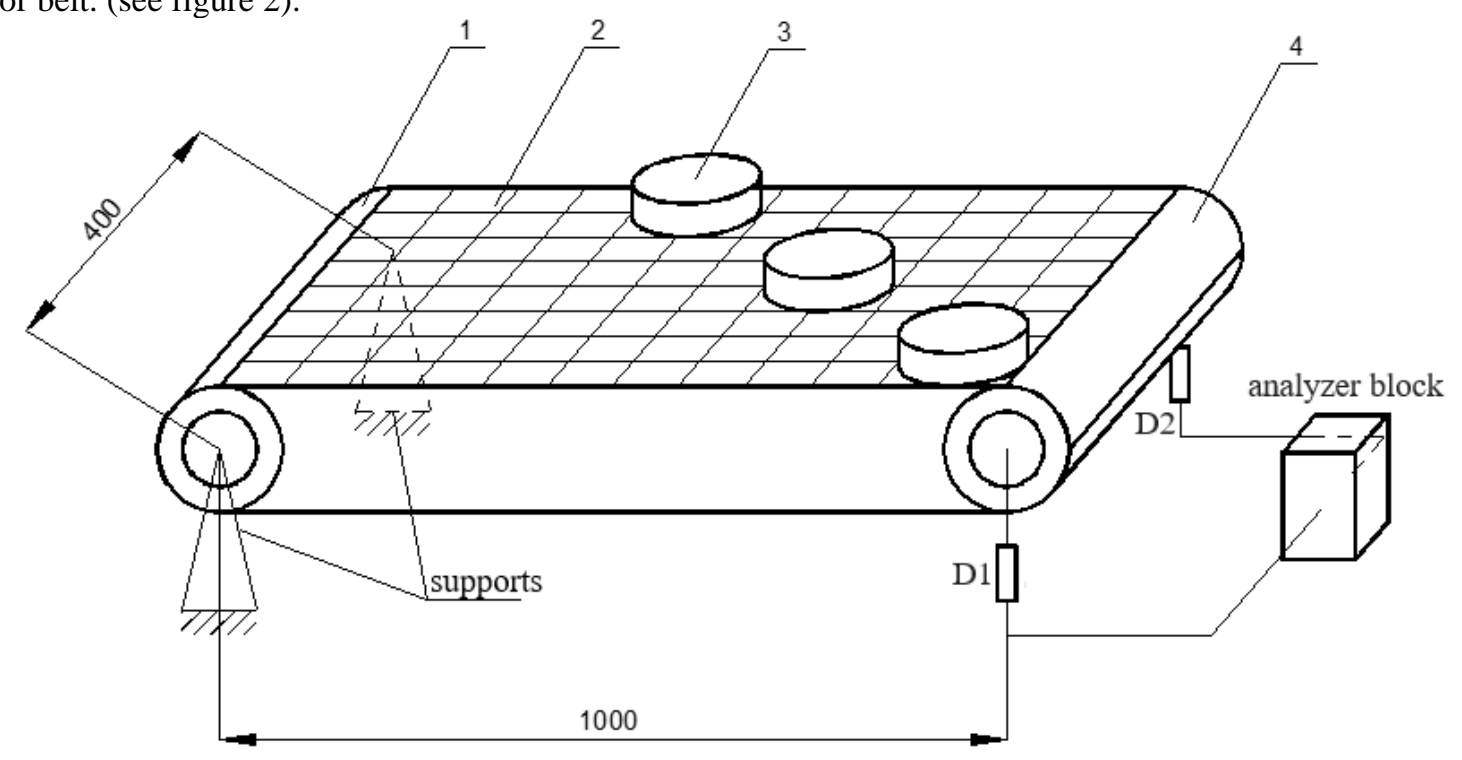

Fig. 2. Kinematic diagram of a flow meter-batcher of various intensities: 1 - drive drum; 2 - conveyor belt; 3 - options for the location of the object to be weighed on the conveyor belt; 4 - driven drum; D1, D2 - load cells

The analyzer unit is designed to collect information from strain gauges [1]. The technical and metrological characteristics of the prototype metering device of various intensities are shown in Table 1.

\begin{tabular}{|c|c|c|}
\hline № & Name of metrological and technical characteristics & Value \\
\hline 1 & Maximum performance limit (MPL), [tons/hour] & up to 1000 \\
\hline 2 & Minimum performance limit, [MPL.\%] & 10 \\
\hline 3 & Limits of permissible error, [MPL.\%] & $\pm 0,5$ \\
\hline 4 & Power consumption, not more than, $[\mathrm{kW}]$ & 1,5 \\
\hline 5 & Maximum bulk density of material, [tons $\left./ \mathrm{m}^{3}\right]$ & 1,4 \\
\hline 6 & Maximum conveyor belt speed, not more than, $[\mathrm{m} / \mathrm{s}]$ & 0,6 \\
\hline 7 & Conveyor belt width, $[\mathrm{m}]$ & $0,3 \ldots 1,6$ \\
\hline 8 & Conveyor belt length, $[\mathrm{m}]$ & $0,3 \ldots 1,5$ \\
\hline 9 & Power supply parameters voltage [V], frequency [Hz] & $350 \pm 10[\mathrm{~V}], 50 \pm 1[\mathrm{~Hz}]$ \\
\hline 10 & Probability of no-failure operation after 2000 hours, [\%] & 0,92 \\
\hline 11 & Operating temperature range, $\left[{ }^{\circ} \mathrm{C}\right]$ & from minus 10 to plus 40 \\
\hline 12 & Total average service life of flow meter-batcher, [years] & 10 \\
\hline 13 & $\begin{array}{l}\text { Communication interface with the upper level automatic control } \\
\text { system }\end{array}$ & $\begin{array}{c}\text { PROFIBUS DP, ETHERNET } \\
\text { (ModBus TCP), ModBus } \\
\text { RTU, 4-20 mA }\end{array}$ \\
\hline 14 & Degree of protection & IP54 \\
\hline
\end{tabular}

Table 1. Technical and metrological characteristics of the prototype of the flow meter-batcher

\section{Control system flow meter-batcher}

The technological process is controlled and controlled by an automatic control system, which ensures the dosing accuracy and productivity. As a rule, in a modern enterprise, a person is engaged in monitoring activities, fixing production errors, accidents and other technological influences on various visualization systems.

The main link of automatic systems is a control cabinet, which, as a rule, includes a controller [7], [9]. This device contains in its memory the entire control program in the form of an algorithmization of the production process. The control cabinet of the developed prototype of the flow meter-batcher of various intensities is shown in Figure 3.

The cable duct (positions 1 and 2) is intended for wiring. The DIN rail (position 3) holds all components that are securely fastened. The discrete input-output module 4 controls the discrete contacts of the printed circuit board 6 . The analog input-output module 5 controls the analog contacts of the printed circuit board 6. A central processor 29 is installed on the mounting base 7 , on which the program is executed, the communication module 12 , which provides information exchange via the Ethernet interface, a dummy module 30 protecting the empty slots of the mounting base 7 . 


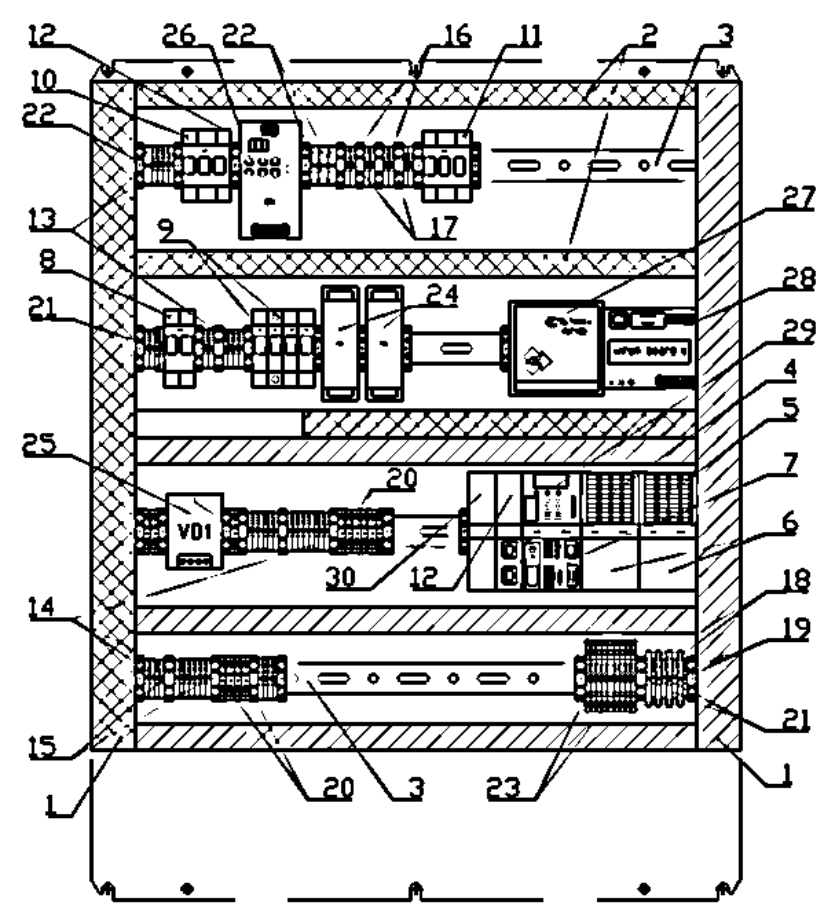

a)

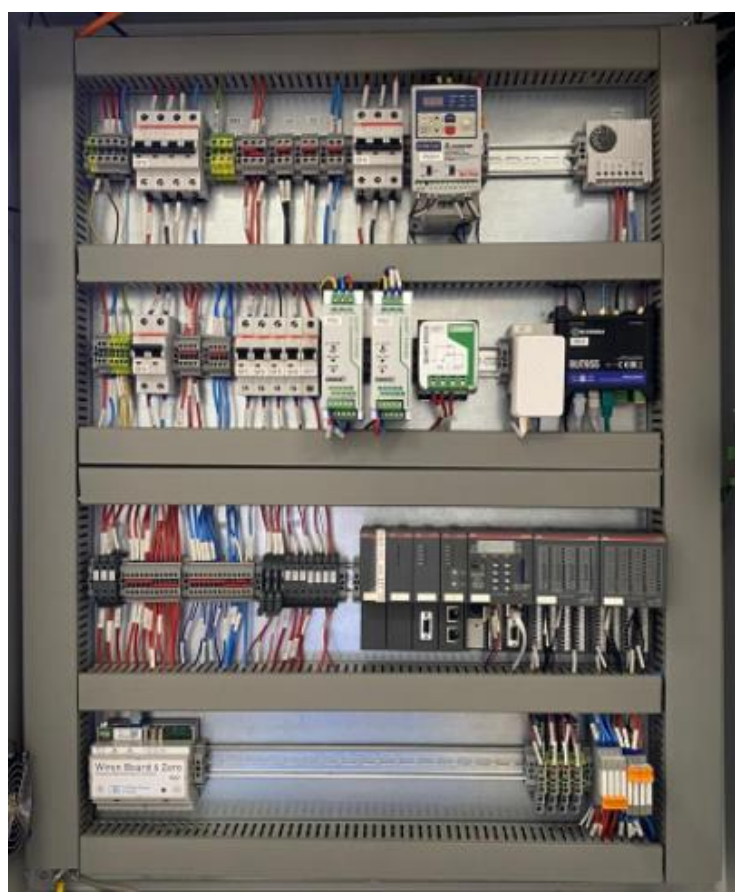

b)

Fig. 3. Control cabinet of a prototype FMB of various intensities: a) block diagram; b) appearance

Circuit breaker 8 is a 220V AC input breaker. Circuit breakers 9 are designed to protect devices against overload and short-circuit currents, powered by $220 \mathrm{~V}$ AC. Automatic machine 10 - an introductory automatic machine for alternating current 380V. Circuit breaker 11 to protect the induction motor against overload and short circuit currents. The end stops 13 make it easy to install and separate the entire product into conventional cells. To a terminal with a cross section of 2.5 $\mathrm{mm}^{2} 14$, wires with a copper conductor cross section of no more than $2.5 \mathrm{~mm}^{2}$ are connected.

The end insulator 15 covers the open part of the terminal. To a terminal with a cross section of $6 \mathrm{~mm}^{2} 16$, wires with a copper conductor cross section of no more than $6 \mathrm{~mm}^{2}$ are connected. The end insulator 17 covers the open part of the terminal. Three-level terminals 18 interconnect the information-measuring circuit and the printed circuit board 6 . The end insulator 19 closes the open part of the three-level terminal. Fuse links are inserted into safety terminals 20 , which provide a constant current against overload and short-circuit currents.

The ground terminals (keys 21 and 22) are ground points and connect to all AC devices and metering channel screens. Relay module 23 provides galvanic isolation between digital inputs / outputs and digital signals. Power supplies 24 convert $220 \mathrm{VAC}$ to $24 \mathrm{VDC}$ for DC powered devices. The decoupling diode 25 reserves the voltage from the power supplies 24 in case of failure of one of them. The frequency converter 26 converts the $380 \mathrm{~V}$ AC frequency to control the rotational speed of the asynchronous motor shaft. LTE router 27 is used to connect the entire system to the Internet via the LTE wireless data transmission standard [10]. A universal controller 28 is required for storing telemetry and transmitting it to peripheral devices [12].

\section{Automatic control system architecture of flow meter-batcher}

The developed automatic control system (ACS) model is conventionally divided into three levels: upper level (informational); basic level (manager); lower level (field level: sensors, actuators, etc.)

Typically, each level has the following content:

a) dispatch level: at this level physical switches and routers should be installed, as well as software that allows the operator to work remotely from the production process [13];

b) middle level: this level is physically filled with controllers, expansion modules for them, directly by the program for controlling the technological process of the considered production [14];

c) lower level: sensors, actuators and other devices.

Figure 4 shows a diagram of an ACS for FMB of various intensities. The block diagram includes: TP - touch panel, PLC - programmable logic controller, FC - frequency converter, EN - encoder, SGT - strain gauge transducer, FMB flow meter-batcher, SG - strain gauge, AM - asynchronous motor, RAW - remote automated workstation, CC - cross cabinet. 


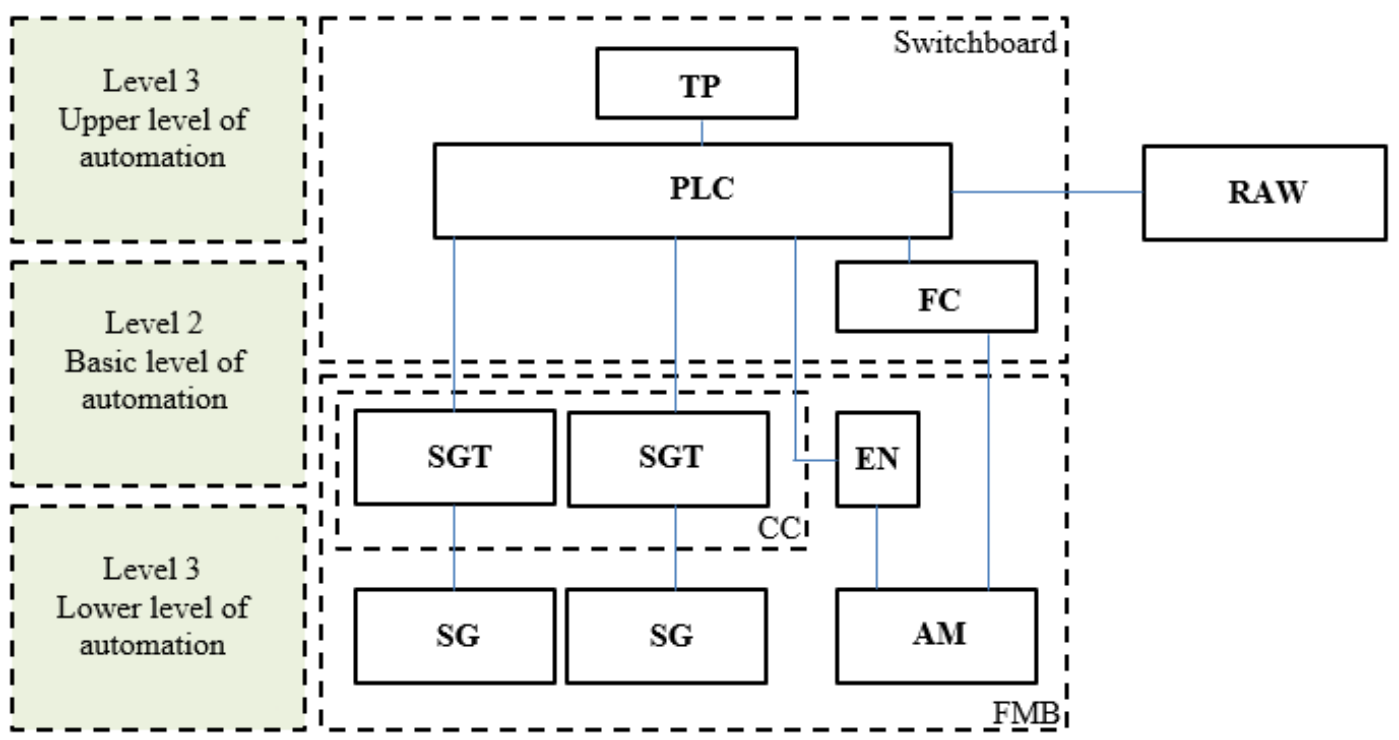

Fig. 4. Block diagram of the automatic control system

The encoder is connected via a cross-connect cabinet. Figure 5 shows the wiring diagram of the control system of the flow meter-batcher. The TELTONIKA RUT955 router acts as a device for connecting to the network via Ethernet cables and Wi-Fi connections.

On LAN ports, it communicates between the following devices:

a) The LAN1 connector connects to the Wiren Board 6 Zero universal automation controller equipped with 2 Ethernet and USB ports and intended for use as an Iridium application server. Receives and transmits data via Modbus protocol from ABB PLC;

b) The LAN2 connector is connected to the ABB AC500 industrial controller, which, using the Modbus protocol, transmits data from the device to the Weintek panel and to the Wiren Board controller. All algorithms running in the system take place in this device;

c) Connector LAN3 is connected to the Weintek MT8070iH touchscreen graphic operator panel and is used to control, display and enter information, serves as a human-machine interface [11]. Due to the high degree of protection IP65, the use of such a device is safe in industry.

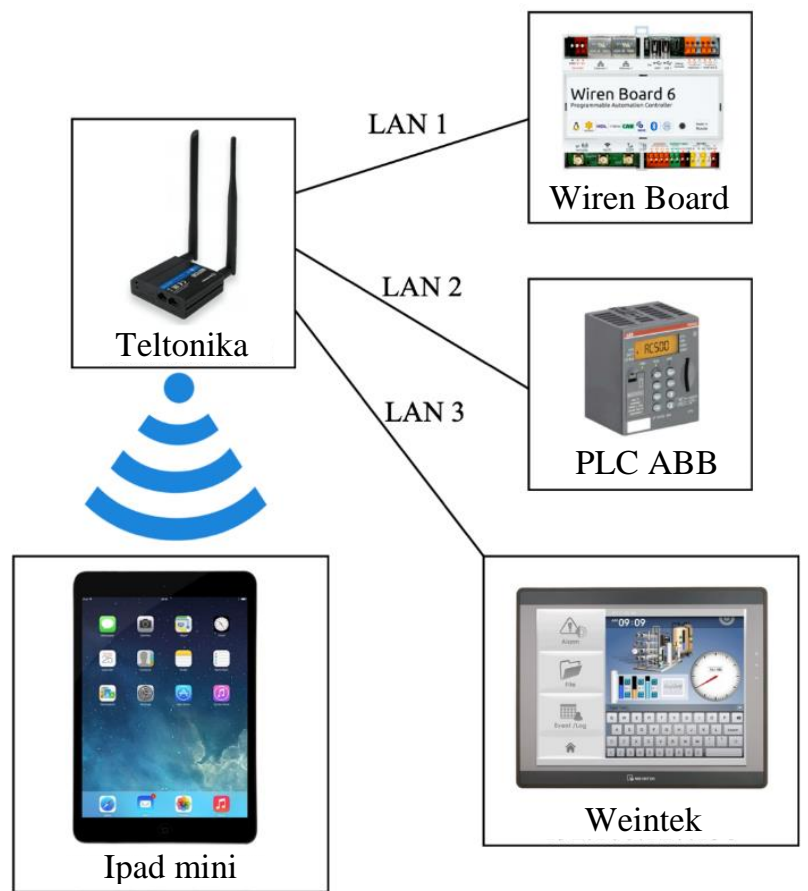

Fig. 5. Wiring diagram of the control system of the flow meter-batcher 
Using a Wi-Fi connection, the router transmits values to the Ipad mini, which receives data from the Wiren Board controller to display and set system parameters, without the need for an operator or operator near the installation.

\section{Conclusion}

As part of the work, a physical model of a prototype of a flow meter-batcher of various intensities and an automatic control system providing both remote and local control of the installation were developed. The planned experiments with FMBs of various intensities will make it possible to determine the optimal range of operating speeds of such installations and the margin of permissible error, the knowledge of which, in turn, will make it possible to form a calibration table of the technical characteristics of FMBs of various productivity and production intensity. It is also worth noting that the developed control system is scalable, and its configuration makes it possible to integrate it into almost any production.

\section{Acknowledgments}

The presented results in the work under consideration were obtained during the implementation of research and development work with funding from the Fund for Assistance to the Development of Small Forms of Enterprises in the Scientific and Technical Sphere. The Fund for Assistance to Small Innovative Enterprises in Science and Technology (Fund for Assistance to Innovation) is a Russian non-profit organization established by the Government of the Russian Federation. The goals of the fund are stated - financial support for young innovators and small businesses who are engaged in high-tech developments with the potential for commercialization.

\section{References}

[1] Shilin, D.; Shestov D. \& Ganin E. (2019). Improving the Accuracy of Weighing Bulk Materials in a Dispenser OnStream Flow Meter with Two Strain Gauges. Vestnik MPEI. № 3 (3). pp. 116-123, ISSN: 1993-6982.

[2] Gordon, S.I. \& Guilfoos B. (2017). Introduction to Modeling and Simulation with MATLAB® and Python, Berkeley: Taylor \& Francis, 2017. 211 p.

[3] Hua, Z.; Zhijiong L. \& Rixing C. (2013). New automatic rubber mixer batching and weighing control system. Journal of weighing apparatus. 2013. pp. 1-6.

[4] Jackson, W. (2004). Livestock Farming.

[5] Klee, H. (2007). Simulation of Dynamic Systems with MATLAB and Simulink. CRC Press, 2007.784 p.

[6] Kuo, B.C. (1995). Automatic Control Systems. 7th Edition, Englewood Cliffs New Jersey: Prentice-Hall Inc, 1995. $1003 \mathrm{p}$.

[7] Lieberwirth, H. (1994). Design of belt conveyors with horizontal curves. Bulk Solids Handling. № \# 14. C. 283285.

[8] Maksarov, V; Zlotnikov, E \& Olt, J. Determining the Load on Support Rollers the Pipe Conveyor Belt, Proceedings of the 28th DAAAM International Symposium, ISBN 978-3-902734-11-2, ISSN 1726-9679, Vienna, Austria, pp.0209-0215.

[9] Lodewijks, G. (1995). The Tow-Dimensional Behaviour of Belt Conveyors. Proceedings of the Beltcon 8 Conference, Pretoria, South Africa. pp. 24-26.

[10] Umoren, M.; Essien, A. \& Ekpoudom I. (2016). Design and implementation of conveyor line speed synchroniser for industrial control applications: A case study of champion's breweries PLC, UYO. Nigerian Journal of Technology. № 3 (35). 619 p.

[11] Vasilyev, A.N.; Vasilyev, A.A.; Shestov, D.A. \& Shilin, D.V. (2019). Mathematical Modeling of the Work of the Flow-Meter Flowmeter-Doser. pp. 293-299.

[12] Devendra, K. C. (2009). Modeling and Simulation of Systems Using MATLAB and Simulink. Chaturvedi, Berkeley: Taylor \& Francis, $734 \mathrm{p}$.

[13] Lieberwirth, H. (1994). Design of belt conveyors with horizontal curves. Bulk Solids Handling. № 14. pp. $283-285$.

[14] McGlinchey, D. (2008). Bulk Solids Handling. Singapore: C.O.S. Printers Pte Ltd, 2008. 290 p. 